\title{
Feature Analysis and Comparison of Prediction Methods for Fire Accidents
}

\author{
Jiyu Zheng ${ }^{1 *}$, Lingbo Zhang ${ }^{2}$, Jiankun Gong ${ }^{2}$, Wenkun Wang ${ }^{1}$ \\ ${ }^{1}$ School of Resources and Safety Engineering, Henan University of Engineering, Zhengzhou 451191, China \\ ${ }^{2}$ School of Energy \& Environment Engineering, Zhongyuan University of Technology, Zhengzhou 450007, China
}

Corresponding Author Email: zhengjiyu@haue.edu.cn

https://doi.org/10.18280/ijsse.100516

Received: 28 May 2020

Accepted: 17 August 2020

Keywords:
fire, production safety accident, grey
prediction, grey Markov prediction,
preventive measures

\section{Keywords:} prediction, grey Markov prediction, preventive measures

\begin{abstract}
Fire is one of the most common production safety accident. The trend of fire can be mastered by analyzing the historical data. This paper explores the features of recent fires in China, predicts fire by two methods, namely, grey theory, and grey Markov theory, and compares the prediction results of the two methods. The results show that: the number of fires in China increased greatly in 2013; Since 2014, the number of fires, as well as the number of deaths, the number of injured, and property loss induced by fires were declining. The maximum relative error of grey prediction was $5.8 \%$, and that of grey Markov prediction was 5\%; grey theory is less accurate in fire prediction than grey Markov prediction. According to the causes and features of fires, several preventive measures were put forward. The research results provide insights into the prevention of fires and protection of production safety.
\end{abstract}

\section{INTRODUCTION}

Production safety accidents refer to the accidents that occur suddenly in the production and operation activities of the producer and operator, which threaten personal safety and health, damage equipment and facilities, or bring economic losses, forcing the said activities to suspend or terminate. Fire is the most common production safety accidents, even more frequent than traffic accidents. Fire might occur in a variety of places, ranging from buildings, vehicles, to operation sites. Many fires have taken place over the years, in urban area or rural area, in residential communities or factories, on the ground or underground, resulting in heavy casualties and property losses [1-3]. Special attention should be paid to fire, due to its wide range and high frequency. To effectively prevent fire, it is necessary to master the law of fire occurrence by analyzing the statistics on previous accidents [4-6].

Statistical analysis on previous accidents mainly focuses on the cause, location, time, type, casualties, and property loss [712]. The trend of fire occurrence could be independently or jointly predicted by the following methods: grey prediction, neural network prediction, and accident system prediction [1315]. Grey means uncertainty, which is a defining feature of the occurrence and development of fire. The grey system theory [16] holds that uncertain phenomena must have certain internal laws [17]. The regularity of any grey series can be revealed by a generation method that weakens its stochasticity. The grey prediction method has been improved by heuristic and Markov methods $[18,19]$. The Markov theory kicks off a series of research into a stochastic process with no aftereffect, i.e. the Markov process. So far, grey and grey Markov methods have been widely applied to forecast traffic accidents, construction accidents, fire, population planning, and economic development [20-22].
Many scholars have attempted to predict fire with various intelligent methods. For instance, Kim and Kim [23] collected online articles on fires in construction sites, and conducted big data analysis on the factors of such fires, including analyzed fire accident factors in construction areas with big data, including time, place, inducement, and season. Kim et al. [24] investigated the fires in underground utility tunnels, and proposed management measures for fire safety. Based on the law of building fire occurrence and development, Emmons [25] came up with a new fire prediction method, and compared the prediction results with the measured results. Leveson et al. [26] analyzed fires with the accident system model, providing new insights into the causes and influencing factors of fire. Yuan et al. [27] combined grey prediction model with backpropagation neural network (BPNN) into a hybrid high-accuracy fire prediction model. Ren et al. [28] examined the causes, features, and consequences of tunnel fires, and grasped the laws of time, location, and vehicle type of such fires. $\mathrm{Li}$ and $\mathrm{Hu}$ [29] proposed a grey Elman network model, which combines grey theory with neural network. Facing the growing number of fires in rural areas, Liu et al. [30] presented a grey prediction model to enhance the fire prevention and promote the fire extinguishing in rural areas. Lin et al. [31] described the dynamic process of fire by catastrophe theory, and modeled and analyzed subway fires. Ding et al. [32] established a general framework for quantitative risk management of warehouse fires, put forward targeted safety measures, and evaluated their reduction effect on the risk of warehouse fires. Mutmainnah et al. [33] adopted the novel 4M Overturned Pyramid (MOP) model to classify fires and explosions starting from the deck of passenger ships.

Through the above analysis, this paper summarizes the features of fires based on historical data, carries out grey prediction and grey Markov prediction of fire accidents, and compares the prediction results between the two methods. 


\section{FEATURE ANALYSIS}

Figure 1 shows the statistics of fires in China in the 21 years from 1998 to 2019. It can be seen that, the number of fires was on the rise since 1998 , reaching the first peak $(258,315)$ in 2002. Then, the number of fires started to decline all the way to the valley $(125,417)$ in 2011 . Since 2012 , the number of fires rebounded. The rebound was very obvious in 2013. In 2012, a total of 152,000 fires were reported in China. That number surged up to 389,000 in 2013, about 2.56 times of 2012 , and further grew to the peak of 395,052 in 2014. Due to the rapid social development, the relatively early data cannot reflect the current fire situation. Hence, only the fire data in 2013-2019 were adopted for subsequent analysis.

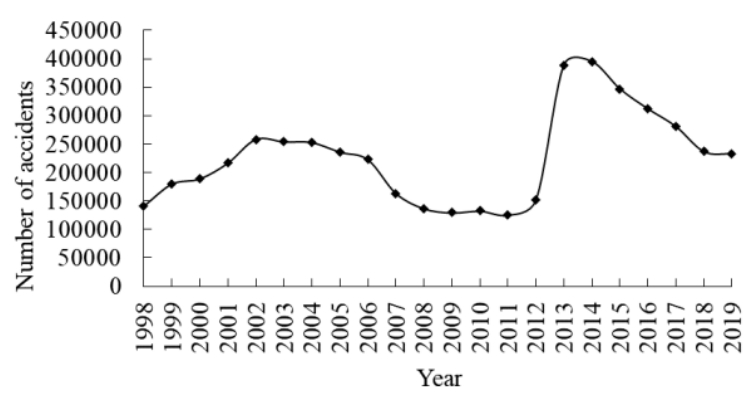

Figure 1. The number of fires in 1998-2019

The statistics on fire, a common accident in life and production, mainly cover four aspects: the number of accidents, the number of deaths, the number of injured, and property loss. The relevant data were collected from China Fire Services. As shown in Figure 2, the number of fires in China exhibited a downward trend from 2013 to 2019. The peak value was 395,052 in 2014 , while the minimum was 233,000 in 2019 , down by $41 \%$ from the level in 2014 . The death toll of fires also declined: In 2019, the number of deaths dropped by $36.8 \%$ to the minimum of 1,335 from the peak $(2,113)$ in 2013.

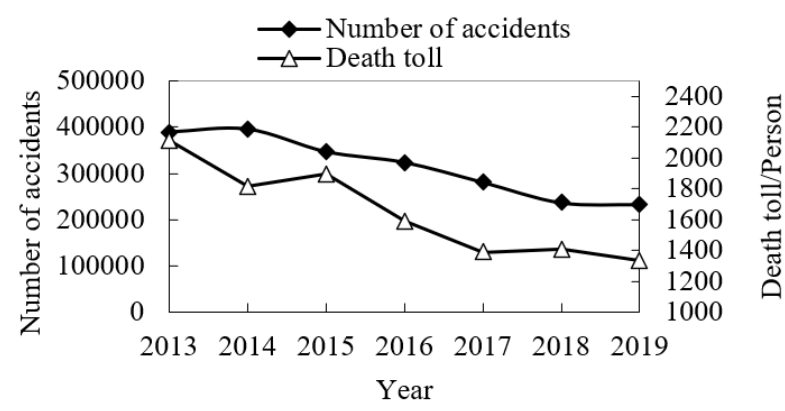

Figure 2. The number of fires and death toll

As shown in Figure 3, from 2013 to 2017, the property loss induced by fires plunged by $25.7 \%$; from 2017 to 2019 , the property loss induced by fires changed slightly, and maintained at around RMB 3.6 billion yuan. The number of injured caused by fires exhibited a downward trend: from 2013 to 2017 , the number of injured dropped clearly by $46.2 \%$; from 2017 to 2019 , that number basically remained at around 800 .

Despite the growing number of fires in some years, the death toll of fires did not increase, but decreased for the following reasons: First, the fire facilities have been constantly improved to effectively put out small and early-stage fires, and the fire-fighting access has been managed well, enabling timely evacuation in fire; Second, the fire department has been actively improving its equipment and efficiency, and trying to arrive at the fire scene in time to prevent the loss of personnel and property; Third, the residents are increasingly aware of the importance of fire safety, and the success rate of self-rescue is on the rise, thanks to fire safety education.

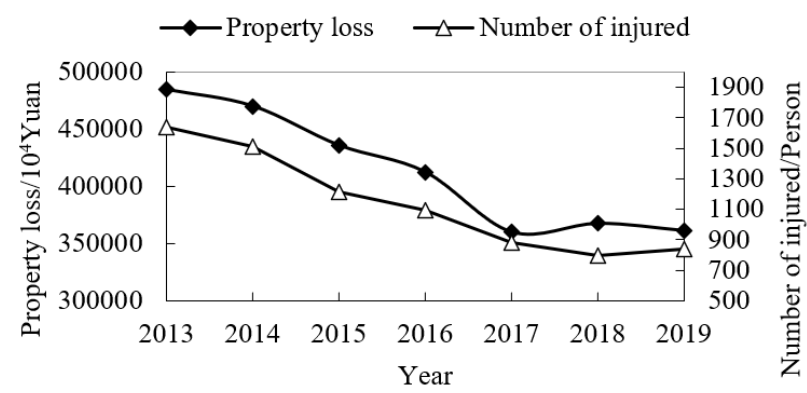

Figure 3. The number of injured and property loss

\section{GREY PREDICTION OF FIRE OCCURRENCE}

\subsection{Grey prediction model}

The fire data of multiple years form a data series. Albeit their complex representations, the data series have overall functions and inherent laws. According to the grey theory, the regularity of any grey series can be revealed by a generation method that weakens its stochasticity. First, the original data can be generated by accumulation, subtraction, and weighted accumulation, in order to find the law of system change and generate a data series with strong regularity. Next, the corresponding differential equation can be established to predict the future trend of events. Grey system theory is often used in accident and disaster prediction.

The grey prediction model can be established in the following steps: obtain the original data; generate a data series through accumulation from left to right; calculate the whitening matrix through averaging operation; derive development coefficient a and grey action quantity $b$; set up the prediction expression of GM $(1,1)$ model with $a$ and $b$ as constants.

The original data series $x^{(0)}(t)$ with $n$ statistical indices can be expressed as:

$$
x^{(0)}(t)=\left\{x^{(0)}(1), x^{(0)}(2), \ldots, x^{(0)}(n)\right\}
$$

The data series can be predicted by:

$$
\hat{x}^{(1)}(k+1)=\left[x^{(0)}(1)-\frac{b}{a}\right] e^{-a k}+\frac{b}{a}, k=0,1,2 \cdots, n
$$

where, $\mathrm{a}$ and $\mathrm{b}$ are constants; $x^{(1)}(k+1)$ is the prediction value. The original data can be restored through subtraction:

$$
\left\{\begin{array}{c}
x^{(0)}(1)=x^{(0)}(1) \\
\hat{x}^{(0)}(k)=x^{(1)}(k)-x^{(1)}(k-1)=\left[x^{(0)}(1)-\frac{b}{a}\right]\left(1-e^{a}\right) e^{-a(k-1)}, k>1
\end{array}\right.
$$

where, $x^{(0)}=[388821,395052,346701,323636,281000$, $237000,233000]$ is the original discrete data series; 
$x^{(1)}=[388821,783873,1130574,1454210,1735210,1972210$, 2205210] is the data series generated through accumulation. Then, matrix B can be calculated as:

$$
B=\left[\begin{array}{cc}
-\frac{1}{2}\left[x^{(1)}(1)+x^{(1)}(2)\right] & 1 \\
-\frac{1}{2}\left[x^{(1)}(2)+x^{(1)}(3)\right] & 1 \\
\cdots & \cdots \\
-\frac{1}{2}\left[x^{(1)}(6)+x^{(1)}(7)\right] & 1
\end{array}\right]
$$

Then, the data matrices B and Y can be established as:

$$
B=\left[\begin{array}{ll}
-586347 & 1 \\
-957223.5 & 1 \\
-1292392 & 1 \\
-1594710 & 1 \\
-1853710 & 1 \\
-2088710 & 1
\end{array}\right]
$$

$Y=[395052,346701,323636,281000,237000,233000]^{T}$

$$
\hat{A}=\left[B^{T} B\right]^{-1} B^{T} Y
$$

It can be solved that $a=0.1127, b=459,996.0433$. Substituting $a$ and $b$ values into the differential equation, the prediction model can be obtained as:

$$
x^{(1)}(k+1)=-3692776.54 e^{-0.1127 k}+4081597.54
$$

The prediction series $\hat{x}^{(0)}$ of the original series $x^{(0)}$ can be obtained by restoring the series $\hat{x}^{(1)}(\mathrm{k}+1)$ :

$$
\left\{\begin{array}{l}
x^{(0)}(1)=x^{(0)}(1)=388821 \\
x^{(0)}(k)=440533.82 e^{-0.1127(k-1)}, k>1
\end{array}\right.
$$

\subsection{Model test}

\subsubsection{Residual test}

The proposed model was tested by absolute error and relative error in fire prediction (Table 1).

It can be seen that the relative prediction error averaged at $2.07 \%$, and peaked at $5.8 \%$. Hence, the proposed model has a high prediction accuracy for medium and long terms.

Table 1. The comparison between actual and predicted

\begin{tabular}{ccccc} 
Year & $\begin{array}{c}\text { Actual } \\
\text { value }\end{array}$ & $\begin{array}{c}\text { Predicted } \\
\text { value }\end{array}$ & $\begin{array}{c}\text { Absolute } \\
\text { error }\end{array}$ & $\begin{array}{c}\text { Relative } \\
\text { error }\end{array}$ \\
\hline 2013 & 388,821 & 388,821 & 0 & 0 \\
2014 & 395,052 & $393,581.13$ & $1,470.87$ & 0.0037 \\
2015 & 346,701 & $351,632.72$ & -4931.72 & 0.0142 \\
2016 & 323,636 & $314,155.23$ & $9,480.77$ & 0.0293 \\
2017 & 281,000 & $280,672.14$ & 327.86 & 0.0012 \\
2018 & 237,000 & $250,757.72$ & -13757.72 & 0.0580 \\
2019 & 233,000 & $224,031.62$ & $8,968.38$ & 0.0385 \\
\hline
\end{tabular}

3.2.2 Posteriori error test
The accuracy of our model was tested by posterior error test in the following steps:

Step 1. Calculate the standard deviation of sample data in the model:

$$
S_{1}=\sqrt{\frac{1}{n-1} \sum_{k=1}^{n}\left[x^{(0)}(k)-\bar{x}\right]^{2}}
$$

where,

$$
\bar{x}=\frac{1}{n} \sum_{k=1}^{n} x^{(0)}(k)
$$

Step 2. Calculate the standard deviation of residuals:

$$
\sqrt{\frac{1}{\mathrm{n}-1} \sum_{\mathrm{k}=1}^{\mathrm{n}}\left[\mathrm{e}^{(0)}(\mathrm{k})-\overline{\mathrm{e}}\right]^{2}}
$$

where,

$$
e^{(0)}(k)=x^{(0)}(k)-x^{(0)}(k)
$$

Obtain the mean of the residuals:

$$
\bar{e}=\frac{1}{n} \sum_{k=1}^{n} e^{(0)}(k)
$$

Step 3. Calculate the ratio of posterior error:

$$
C=S_{2} / S_{1}
$$

Step 4. Calculate the small error probability, i.e. the frequency of residuals falling into a certain interval:

$$
p=p\left\{\left|e^{(0)}(k)-\bar{e}\right|<0.6475 S_{1}\right\}
$$

It is obtained that $\bar{x}=315030 ; \quad S_{1}=66959.4284$; $S_{2}=7966.4068 ; C=0.1190 ;\left|e^{(0)}(k)-\bar{e}\right|=(222.63,81248.24$, $5154.35,9258.14,105.23,13798.35,8745.75)$.

The probability of small error is: $p=p\left\{\left|e^{(0)}(k)-\bar{e}\right|\right.$ $\left.<0.6475 S_{1}\right\}=1$

Table 2 lists the index values of posterior error test. It can be seen that $\mathrm{P}=1$ and $\mathrm{C}=0.1190$. Against the accuracy level table (Table 3 ) of grey prediction, the accuracy of our model belongs to level 1 , that is, our model is suitable for medium and long-term prediction.

Table 2. The index values of posterior error test

\begin{tabular}{ccc}
\hline Index & $\mathrm{P}$ & $\mathrm{C}$ \\
\hline Value & 1 & 0.1190 \\
\hline
\end{tabular}

Table 3. The accuracy level table

\begin{tabular}{ccccc}
\hline Level & Applicability & Relative error & C & P \\
\hline 1 & Long-term & $1 \%$ & 0.35 & 0.95 \\
2 & Medium and long term & $5 \%$ & 0.50 & 0.80 \\
3 & Short-term & $10 \%$ & 0.65 & 0.70 \\
4 & Short-term & $20 \%$ & 0.80 & 0.60 \\
\hline
\end{tabular}




\section{GREY MARKOV PREDICTION OF FIRE OCCURRENCE}

Markov chain is a stochastic process with Markov property, which exists in discrete exponential set and state space. Featuring irreducibility, recurrence, periodicity, and ergodicity, Markov chain can be defined by transition matrix and transition graph. Using Markov chain, the future can be predicted only using the latest dynamic data. The causes of fire are stochastic and sudden. Whether the fire will occur in the next moment has nothing to do with the previous moments. This is in line with the features of Markov chain. Based on the number of fires in 2013-2019, grey Markov prediction was carried out in the following steps.

Step 1. Establish the GM $(1,1)$ model.

By GM $(1,1)$ model, it can be obtained that $a=0.1127$, and $b=459,996.0433$.

$$
\begin{aligned}
& \hat{x}^{(0)}(k+1)=\left[x^{(0)}(1)-\frac{b}{a}\right]\left(1-e^{a}\right) e^{-a k} \\
& =\left(1-e^{0.1127}\right)\left[388821-\frac{459996.0433}{0.1127}\right] e^{-0.1127 k} \\
& =440533.82 e^{-0.1127 k}
\end{aligned}
$$

Step 2. Divide the state of samples.

The few samples were divided into three states by the mean value: E1, E2, and E3. The division results are recorded in Table 4.

The divided state data were filled in Table 5.

Table 4. The state division of the number of accidents

\begin{tabular}{cccc}
\hline State & E1 & E2 & E3 \\
\hline$\frac{x^{(0)}(k)}{x^{(0)}(k)}$ & $0.9451 \sim 0.9767$ & $0.9767 \sim 1.0083$ & $1.0083 \sim 1.0400$ \\
\hline
\end{tabular}

Table 5. The number of fires in different states in 2013-2019

\begin{tabular}{ccccc}
\hline Year & $x^{(0)}(k)$ & $x^{(0)}(k)$ & $\frac{x^{(0)}(k)}{x^{(0)}(k)}$ & State \\
& & & 1 & 2 \\
\hline 2013 & 388,821 & 388,821 & 1.0037 & 2 \\
2014 & 395,052 & $393,581.13$ & 0.9860 & 2 \\
2015 & 346,701 & $351,632.72$ & 1.0301 & 3 \\
2016 & 323,636 & $314,155.23$ & 1.0012 & 2 \\
2017 & 281,000 & $280,672.14$ & 0.9451 & 1 \\
2018 & 237,000 & $250,757.72$ & & 3 \\
2019 & 233,000 & $224,031.62$ & 1.0400 & 3 \\
\hline
\end{tabular}

Step 3. Derive the 1-step state transition probability matrix of the number of fires from state division results.

$$
P_{1=}\left[\begin{array}{ccc}
0 & 0 & 1 \\
\frac{1}{4} & \frac{1}{2} & \frac{1}{4} \\
0 & 1 & 0
\end{array}\right]
$$

Step 4. Calculate the predicted number of fires in 2013-2019 (Table 6).

Table 6. The predicted number of fires in 2013-2019

\begin{tabular}{cccccccc}
\hline Year & 2013 & 2014 & 2015 & 2016 & 2017 & 2018 & 2019 \\
\hline Predic & 388, & 390, & 349, & 311, & 278, & 248, & 222, \\
tion & 821 & 649 & 013 & 815 & 581 & 890 & 363 \\
\hline
\end{tabular}

\section{COMPARISON BETWEEN METHODS}

PREDICTION

Both grey method and grey Markov method are applicable for fire prediction. As shown in Table 7, the grey prediction has a maximum absolute error of 13,758 and a relative error of 5.8\%; the grey Markov prediction has a maximum absolute error of 11,890 and a relative error of 5\%. The grey prediction is less accurate than grey Markov prediction.

Table 7. The comparison between prediction methods

\begin{tabular}{cccccc}
\hline Year & Actual value & Gray prediction value & Absolute error & Grey Markov prediction value & Absolute error \\
\hline 2013 & 388,821 & 388,821 & 0 & 388,821 & 0 \\
2014 & 395,052 & 393,581 & 1471 & 390,649 & 4,403 \\
2015 & 346,701 & 351,633 & -4932 & 349,013 & -2312 \\
2016 & 323,636 & 314,155 & 9481 & 311,815 & 11,821 \\
2017 & 281,000 & 280,672 & 328 & 278,581 & 2419 \\
2018 & 237,000 & 250,758 & -13758 & 248,890 & -11890 \\
2019 & 233,000 & 224,032 & 8968 & 222,363 & 10,637 \\
\hline
\end{tabular}

\section{LAWS AND PREVENTIVE MEASURES}

\subsection{Laws of fires}

(1) Regionally speaking, the number of fires moves upward in Central, West, and Northeast China, while the economically developed East China accounts for the largest proportion of fires.

(2) Many fires have caused mass deaths and injuries. The number of deaths takes up a large portion in the casualties of fires. Public gathering places are faced with high fire risk. For instance, major and serious fires often occur in entertainment places, shopping malls, hotels, wholesale markets, family workshops, warehouses, hospitals, and sales offices.

(3) Small business places like self-employed and private enterprises are prone to fire. Labor-intensive production enterprises are more likely to face serious fires.

(4) Fire occur frequently in residential areas, whether in cities or rural areas. The most common fire is electrical fire, which takes up about $60 \%$ of major fires.

(5) Arson occurs occasionally. Fire accidents show a certain regularity in time: Many fires take place in winter and spring, and night fires lead to heavy casualties. 


\subsection{Preventive measures}

(1) Residential fire. Residential fire is more frequent, more deadly, and more economically destructive than any other type of fire. The heavy casualties of residential fire are attributable to the following facts: the decoration materials are inflammable; household appliances are used frequently; people spend a long time, unalert, in their houses at night. Considering these facts, several preventive measures were suggested to prevent residential fire: use high-grade decoration materials to reduce fire occurrence and slow down fire development; install fire alarm and its interlocking devices to detect and report fire early on; stop the non-standard use of electricity and fire at home, lowering the possibility of fire; publicize the knowledge on fire prevention, and organize fire drills frequently, thereby improving the escape and self-rescue abilities of the residents.

(2) Electrical fire. The ubiquity and wide use of household appliances increase the risk of fire. Currently, electrical fire is a major type of fire. The following measures were proposed to prevent electrical fire: implement strict standard for electrical fire prevention, and enhance the safety of household appliances; improve intrinsic safety of electrical equipment, allowing them to automatically cut off the power supply or issue an alarm under abnormal conditions; the enterprises frequently stricken by fire must improve the safety rules and regulations of electrical fire prevention, and step up regular patrol and inspection to eliminate electrical fire hazards in time; publicize the knowledge on safe use of electricity, such that people can use electricity safely and normally.

(3) Fire at business places. Business places are often mixed with residential communities. Any fire at these places will easily cause heavy casualties. Therefore, it is imperative to separate business places from residential communities, and keep a sufficiently large distance between them. In addition, business places should regularly identify fire hazards, record the findings, and eliminate the hazards in time.

(4) Fire in rural areas. The relatively backward rural areas have imperfect fire-fighting facilities. Once a fire breaks out, it is difficult for the urban fire rescue team to reach the fire scene quickly. Therefore, villages and towns should improve the fire infrastructure, and set up full-time or part-time fire teams, depending on the actual conditions; fire safety patrols should be increased, especially in the fire-prone season before and after the Spring Festival; the knowledge on rural fire prevention should be publicized among villagers to effectively prevent fire.

\section{CONCLUSIONS}

This paper summarizes the features of fires through statistical analysis, predicts fires by grey method and grey Markov method, identifies the causes of fires, and puts forward effective countermeasures. The main conclusions are as follows:

(1) The basic features of recent fires in China were analyzed, including the number of accidents, the number of deaths, the number of injured, and property loss. From 2013 to 2017, the relevant indices of fires showed a downward trend; from 2017 to 2019 , the relevant indices changed slightly and remained basically the same.

(2) Grey theory and grey Markov theory were separately used to predict the number of fire accidents. Error analysis shows that the two methods are both applicable to fire prediction, but differ in prediction accuracy.

(3) Comparing the prediction data of grey theory and grey Markov theory, it was learned that the grey prediction has a maximum absolute error of 13,758 and a relative error of 5.8\%; the grey Markov prediction has a maximum absolute error of 11,890 and a relative error of $5 \%$. The grey prediction is less accurate than grey Markov prediction.

(4) After analyzing the fire features, several measures were proposed to prevent residential fire, electrical fire, fire at business places, and fire in rural areas. These measures provide important guidance for fire prevention.

\section{ACKNOWLEDGMENT}

This work is supported by the Doctoral Fund Project of Henan University of Engineering (Grant No.: 2016025).

\section{REFERENCES}

[1] Zhang, G., Zhou, X., Zhu, G., Yan, S. (2019). A new accident analysis and investigation model for the complex building fire using numerical reconstruction. Case Studies in Thermal Engineering, 14: 100426. https://doi.org/10.1016/j.csite.2019.100426

[2] Feng, S.H., Li, Z., He, Y.H. (2017). Statistic data analysis and revelation of aircraft fire accidents based on gray relational method. Safety and Environmental Engineering, 24(3): $138-143, \quad 149$. https://doi.org/10.13578/j.cnki.issn.16711556.2017.03.024

[3] Jia, S.K., Wen, X.H., Jiang, Z.A., Lin, D.J. (2008). Application of grey system theory in urban fire accident prediction. China Work Safety Science and Technology, 4(6): 106-109. https://doi.org/10.3969/j.issn.1673193X.2008.06.024

[4] An, C.H., Wang, J.W. (2008). Grey markov model prediction of fire accidents. Fire Science and Technology, 27(5): 367-370. https://doi.org/10.3969/j.issn.10090029.2008.05.015

[5] Jing, G.X., Wang, W.M., Hao, T.X. (2008). Fire accident prediction based on grey BP network. Industrial Safety and Environmental Protection, 34(2): 61-63. https://doi.org/10.3969/j.issn.1001-425X.2008.02.025

[6] Takeda, K. (2007). How to avoid sudden fire accident of electronic equipments. Journal of The Japan Institute of Electronics Packaging, 10(2): 112-115. https://doi.org/10.5104/jiep.10.112

[7] Liu, S.F. (2014). Grey System Theory and Its Application. Science Press.

[8] Mao, Z.L., Sun, J.H. (2011). Application of GreyMarkov model in forecasting fire accidents. Procedia Engineering, 11: 314-318. https://doi.org/10.1016/j.proeng.2011.04.663

[9] Deng, J.L. (1992). Course of Grey System Theory. Wuhan: Huazhong University of Technology Press.

[10] McNay, J., Puisa, R., Vassalos, D. (2019). Analysis of effectiveness of fire safety in machinery spaces. Fire Safety Journal, 108 : 102859. https://doi.org/10.1016/j.firesaf.2019.102859

[11] Cowsigan, S.P., Renuga, D., Packiavathy, G.S., Mahi, S.V. (2019). Enhancing survival during fire accidents 
using quad copter. South Asia Management Association, 3(3): 25-33.

[12] Chen, M., Wang, K., Guo, H., Yuan, Y. (2019). Human factors of fire and explosion accidents in petrochemical enterprises. Process Safety Progress, 38(4): e12043. https://doi.org/10.1002/prs.12043

[13] Sun, X., Sun, W., Wang, J., Zhang, Y., Gao, Y. (2016). Using a Grey-Markov model optimized by Cuckoo search algorithm to forecast the annual foreign tourist arrivals to China. Tourism Management, 52: 369-379. https://doi.org/10.1016/j.tourman.2015.07.005

[14] Samet, H., Mojallal, A. (2014). Enhancement of electric arc furnace reactive power compensation using GreyMarkov prediction method. IET Generation, Transmission \& Distribution, 8(9): 1626-1636. https://doi.org/10.1049/iet-gtd.2013.0698

[15] Gasparini, M. (1997). Markov chain monte carlo in practice. $\quad$ Technometrics, $39(3)$ : 338. https://doi.org/10.1080/00401706.1997.10485132

[16] Ronquist, F., Teslenko, M., Van Der Mark, P., Ayres, D. L., Darling, A., Höhna, S., Larget, B., Liu, L., Suchard, M.A., Huelsenbeck, J.P. (2012). MrBayes 3.2: Efficient bayesian phylogenetic inference and model choice across a large model space. Systematic Biology, 61(3): 539-542. https://doi.org/10.1093/sysbio/sys029

[17] Green, P.J. (1995). Reversible jump Markov chain monte Carlo computation and Bayesian model determination. Biometrika, 82(4):

$711-732$ https://doi.org/10.1093/biomet/82.4.711

[18] Rabiner, L., Juang, B. (1986). An introduction to hidden Markov models. IEEE ASSP Magazine, 3(1): 4-16. https://doi.org/10.1109/MASSP.1986.1165342

[19] Deng, J.L. (2002). Grey Theory Basis. Huazhong University of Science and Technology Press.

[20] Wu, J.H., Lauh, C.R. (1998). A study to improve GM (1, 1) via heuristic method. The Journal of Grey System, 10(3): 183-192.

[21] Yidan, H.Y.B. (1992). Grey-Markov forecasting model and its application. Systems Engineering-theory \& Practice, 4, 012.

[22] Kumar, U., Jain, V.K. (2010). Time series models (GreyMarkov, Grey Model with rolling mechanism and singular spectrum analysis) to forecast energy consumption in India. Energy, 35(4): 1709-1716. https://doi.org/10.1016/j.energy.2009.12.021

[23] Kim, J.S., Kim, B.S. (2018). Analysis of fire-accident factors using big-data analysis method for construction areas. KSCE Journal of Civil Engineering, 22(5): $1535-$ 1543. https://doi.org/10.1007/s12205-017-0767-7

[24] Kim, D.E., Shin, Y.C., Kwon, Y.J. (2008). A investigation study on the maintenance management for fire safety according to analysis of fire accident in Korea (I). In Proceedings of the Korea Institute of Fire Science and Engineering Conference, pp. 328-333. https://www.koreascience.or.kr/article/CFKO20080694 2460321.page

[25] Emmons, H.W. (1979). The prediction of fires in buildings. In Symposium (International) on Combustion, 17(1): 1101-1111. https://doi.org/10.1016/S00820784(79)80105-8

[26] Leveson, N.G., Allen, P., Storey, M.A. (2002). The analysis of a friendly fire accident using a systems model of accidents. In Proceedings of the 20th International System Safety Conference, pp. 5-9. http://sunnyday.mit.edu/caib/issc-bl-2.pdf

[27] Yuan, P.W., Song, S.X., Dong, X.Q. (2014). Study on fire accident prediction based on optimized grey neural network combination model. Journal of Safety Science and Technology, 10(3): 119-124. https://doi.org/10.11731/j.issn.1673-193x.2014.03.020

[28] Ren, R., Zhou, H., Hu, Z., He, S., Wang, X. (2019). Statistical analysis of fire accidents in Chinese highway tunnels 2000-2016. Tunnelling and Underground Space Technology, 83: 452-460. https://doi.org/10.1016/j.tust.2018.10.008

[29] Li, Y., Hu, S.Q. (2009). The application study of gray elman neural networks to fire accident prediction. China Safety Science Journal, 19(3): 28-31. https://doi.org/10.3969/j.issn.1003-3033.2009.03.005

[30] Liu, L., Xiao, Z.N., Li, Y.J., Lv, S.R., Zhang, J.Y., Tao, T.J. (2010). Renovated gray prediction model for fire damage in the rural area and its application. Applied Mechanics and Materials, 10(2): 162-166. https://doi.org/10.3969/j.issn.1009-6094.2010.02.039

[31] Lin, X., Song, S., Zhai, H., Yuan, P., Chen, M. (2020). Using catastrophe theory to analyze subway fire accidents. International Journal of System Assurance Engineering and Management, 11(1): 223-235. https://doi.org/10.1007/s13198-019-00942-2

[32] Ding, L., Khan, F., Ji, J. (2020). Risk-based safety measure allocation to prevent and mitigate storage fire hazards. Process Safety and Environmental Protection, 135:

282-293. https://doi.org/10.1016/j.psep.2020.01.008

[33] Mutmainnah, W., Bowo, L.P., Nurwahyudy, A., Prasetyo, F.A., Furusho, M. (2020). Causative factor analysis of passenger ship accident (Fire/Explosion) in Indonesia. In IOP Conference Series: Earth and Environmental Science, 557(1): 012037. https://doi.org/10.1088/1755$1315 / 557 / 1 / 012037$ 